\title{
PARACOCCIDIOIDOMICOSE SUBAGUDA PROGRESSIVA. TRATAMENTO DE UM DOENTE COM ANFOTERICINA B E NUTRIÇÃO PARENTERAL
}

\author{
Paulo Camara Marques PEReira (1), Benedito Barkaviera (1), Jussara Marcondes (1), Celso \\ Vieira Souza LEITE (2), Domingos Alves MEIRA (3), Tadasi INOUE (4) e José MORCELI (1)
}

\section{R E S U M O}

Os Autores descrevem um caso de paracoccidioidomicose subaguda progressiva, com quadro clínico sugestivo de síndrome de má absorção, em que o doente não se beneficiara apenas com o tratamento antifúngico convencional. Ao se introduzir como medida auxiliar a nutrição parenteral houve evidente melhora clínica e laboratorial. Desta maneira os Autores propõe o uso associado da nutrição parenteral no tratamento de doentes com esta forma clínica de paracoccidioidomicose.

\section{N T ROD U G $\tilde{A} \mathbf{O}$}

A Paracoccidioidomicose da criança e do adolescente manifesta-se com frequîência pela forma denominada juvenil da doença ${ }^{6}$, que evolui com acometimento ganglionar predominante. A poliadenopatia aguda ou subaguda com localização preferencial nas cadeias linfáticas: cervical, sub-mandibular, axilar e mesentérica é comum na primeira e segunda décadas da vi da. Nestes doentes os gânglios enfartados são pouco dolorosos, de tamanho variáveis e costumam fistulizar. Baço, fígado e medula óssea frequentemente são acometidos. O comprometimento do tubo digestivo, nesta forma de paracoccidioidomicose, é comum sendo o quadro clínico decorrente das alterações anatômicas ou apenas funcionais de alguma parte do intestino delgado ou dos segmentos cólicos 1 . Muitas vezes associam-se às alterações intestinais da doença, às do sistema linfático abdominal, acarretando quadro clínico semelhante ao encontrado em portadores de linfangiectasia intestinal ${ }^{8}$. Nestes casos o doente tem perda im- portante de proteínas tanto para a luz intestinal, quanto para o interior da cavidade peritoneal, além de apresentar má absorção de gorđuras ${ }^{5}$. A perda de proteínas determina hipoalbuminemia com todas as suas consequências, além da depressão das imunidades celular e humoral ${ }^{9}$, agravando ainda mais as condições do doente.

A denominação de paracoccidioidomicose subaguda progressiva, parece ser mais adequada para representar a forma juvenil com comprometimento linfático abdominal acompanhada de hipoalbuminemia e má absorção, por dar idéia da gravidade e do caráter evolutivo dessa forma de doença, ao invés de ater-se apenas ao grupo etário.

A nutrição parenteral, à base de carboidratos, aminoácidos, vitaminas, gorduras e minerais é indicação importante para o tratamento de doentes debilitados, incapacitados para a nutrição oral e com defeitos de absorção in-

(1) Auxiliar de Ensino do Departamento de Moléstias Infecciosas e Parasitárias, Dermatologia e Rađiologia da Faculdade de Medicina do Campus de Botucatu - UNESP. Botucatu, São Paulo, Brasil

(2) Auxiliar de Ensino do Departamento de Cirurgia e Ortopedia da Faculdade de Medicina do Campus de Botucain - UNESP. Botucatu, São Paulo, Brasil

(3) Professor Titular do Departamento de Moléstias Infecciosas e Parasitárias, Dermatologia e Radiologia da Faculdade de Medicina de Botucatu - UNESP. Botucatu, São Paulo, Brasil

(4) Médico Residente da Disciplina de Gastroenterologia do Departamento de Cirurgia e Ortopedia da Faculdade de Medicina do Campus de Botucatu - UNESP. Botucatu, Săo Paulo, Brasil 
PEREIRA, P. C. M.; BARRAVIERA, B.; MARCONDẼ, J.; LEITE, C. V. S.; MEIRA, D. A.; INOUE, T. \& MORCELI J. - Paracoccidioidomicose subaguda progressiva. Tratamento de um doente com anfotericina B e nutrição paren teral. Rev. Inst. Med. trop. São Paulo 27:268-273, 1985

testinal ${ }^{4}$. De acordo com DUDRICK ${ }^{3}$ não há nenhuma entidade nosológica na qual o mau estado nutritivo, deva ser preferível ao equilíbrio energético satisfatório.

O objetivo da apresentação de um caso de paracoccidioidomicose subaguda progressiva justifica-se pela indicação da nutrição paren. teral como forma indispensável de terapêutica associada à anfotericina $\mathrm{B}$.

\section{DESCRIÇÃO DO CASO}

J.C.S. - 21 anos, masculino, preto, solteiro, tratorista de lavoura, natural e procedente da zona rural de Itaí - SP.

H.M.A. - Aparecimento de nódulos nas regiōes retroauriculares direita e esquerda há 6 meses. Nódulo na região infra-mamária esquerda há 3 meses. Há 2 meses aparecimento de vários nódulos semelhantes aos anteriores, na região sub mandibular, que aumentaram de tamanho tornando-se amolecidos. Nesta épo. ca os dois nódulos das regiões retroauriculares direita e esquerda tornaram-se amolecidos e começaram a drenar material espesso de cor esverdeada. Há um dia outro nódulo da região cervical também começou a drenar material com as mesmas características já descritas.

Tem apresentado febre baixa no período da tarde e inicio da noite, acompanhada de tremores e às vezes de arrepios de frio, desde o inicio do quadro, assim como, olhos amarelados e escurecimento da urina.

I.S.D.A. - Fraqueza, indisposição para o trabalho, emagrecimento desde o início da doença. Há 15 dias, edema do joelho direito sem sinais inflamatórios.

\section{Antecedentes epidemiológicos}

E tratorista de lavoura, tendo trabalhado com cultura de feijão, café, arroz e cana. Fuma 5 a 6 cigarros por dia.

\section{Exame físico geral}

$\mathrm{PA}=130 / 70 \mathrm{mmHg} ; \mathrm{P}=\mathrm{FC}=88 \mathrm{bat} / \mathrm{min}$; $\mathrm{T}=36,8^{\circ} \mathrm{C} ; \mathrm{F} R=20 \mathrm{mov} / \mathrm{smin}$.

Doente em regular estado geral, contactando bem $o$ ambiente. Icterícia conjuntival ++ .

Pele: presença de duas fístulas com drenagem de material de aspecto esverdeado nas re. giões retroauriculares direita e esquerda.
Tecido celular subcutâneo: presença de nó dulo na região infra mamária esquerda de um centímetro de diâmetro, móvel, duro, indolor não coalescente, não fistulizado e não ađerente a planos profundos.

Mucosas: úmidas e descoradas.

\section{Linfonodos}

\section{Cadeias superficiais}

Cadeias retroauriculares direita e esquerda: presença de um gânglio de cada lado, aumentados quatro vezes de tamanho, amolecidos, aderentes a planos profundos, indolores, drenando secreção amarelo-esverdeada.

Cadeias: cervicais anteriores e posteriores, submandibulares, supraclaviculares e axilares com gânglios, aumentados de tamanho, endure. cidos, coalescentes, não aderentes a planos profundos, indolores e não fistulizados.

\section{Cadeias profundas}

Abdominais: presença de nódulos coalescentes na região periumbilical com aproximadamente dez centímetros de diâmetro, consis. tência aumentada, móveis, indolores à palpação profunda.

Musculatura: normotrófica, normotônica.

\section{Exame físico especial}

Segmento cefálico: sem alterações.

Pescoço: aumentado de volume devido aos linfonodos, dando o aspecto de pescoço taurino.

Tórax: semiologicamente normal.

Abdome: plano, tenso à palpação, presença de massas periumbilicais já descritas. Ruídos hidro-aéreos presentes e normais.

Fígado: percutível a partir do quinto espa. ço intercostal direito, até mais ou menos quatro centímetros do rebordo costal direito. Palpável a quatro centímeros do rebordo costal direito e a mais ou menos dez centímetros do apêndice xifóide, indolor, consistência normal

Baço: percutível a partir do oitavo espaço intercostal esquerdo, até mais ou menos dois 
PEREIRA, P. C. M.; BARRAVIERA, B.; MARCONDES, J.; LEITE, C. V. S.; MEIRA, D. A.; INOUE, T. \& MORCEIJ.,

J. - Paracoccidioidomicose subaguda progressiva. Tratamento de um doente com anfotericina B e nutriçăo parenteral. Rev. Inst. Med. trop. São Paulo 27:268-273, 1985.

centímetros do rebordo costal esquerdo, onde é palpável, apresentando-se indolor, com consistência aumentada.

Genitais: semiologicamente normais.

Membros: presença de edema duro no joetho direito, indolor, sem sinais inflamatórios.

Sistema nervoso: semiologicamente normal.

\section{DIAGNÓSTICO E EVOLUĢ̃̃O CLINICA}

O doente foi internado na Enfermaria de Moléstias Infecciosas e Parasitárias da Faculdade de Medicina de Botucatu, no dia 13 de abril de 1982. Por intermédio do exame micológico direto do material de secreção de gânglios fistulizados, demonstrou-se o Paracoccidioides brasiliensis. Os exames laboratoriais evolutivos encontram-se expressos na Tabela I.

$T$ A B E I A I

Evoluçāo dos exames subsidiários antes e após a nutrição parenteral

\begin{tabular}{|c|c|c|c|c|c|c|c|c|c|c|c|}
\hline \multicolumn{5}{|l|}{ Nutrição parenteral } & \multicolumn{4}{|c|}{$I^{*}$} & \multicolumn{3}{|l|}{$I^{* *}$} \\
\hline \multicolumn{12}{|l|}{$\begin{array}{l}\text { Exames } \\
\text { subsidiários }\end{array}$} \\
\hline Hematócrito $(\%)$ & 32 & 29 & 23 & 24 & 31 & 25 & 23 & 30 & 28 & 28 & 39 \\
\hline Glóbulos brancos $\left(/ \mathrm{mm}^{3}\right)$ & 22600 & 23300 & 12200 & 14400 & 17600 & 17900 & 13000 & 16800 & 14200 & 9030 & 7300 \\
\hline Segmentados $(\%)$ & 73 & 85 & 78 & 86 & 86 & 81 & 82 & 71 & 64 & 75 & 60 \\
\hline Linfócitos $(\%)$ & 22 & 4 & 17 & 10 & 5 & 10 & 12 & 10 & 13 & 13 & 31 \\
\hline Eosinófilos $\quad(\%)$ & 2 & 1 & 0 & 0 & 0 & 1 & 0 & 3 & 14 & 10 & 3 \\
\hline Monócitos $(\%)$ & 3 & 10 & 5 & 2 & 9 & 8 & 6 & 16 & 9 & 2 & 6 \\
\hline V.H.S. $\quad(\mathrm{mm} / \mathrm{h})$ & 58 & 61 & 69 & 65 & 46 & 55 & - & 60 & 53 & - & 8 \\
\hline Albumina $(\mathrm{g} / \%)$ & 2,1 & - & 2,3 & 2,7 & - & - & 2,8 & 3,8 & 3,2 & 3,18 & 3,9 \\
\hline Globulinas $(\mathrm{g} / \%)$ & 6,1 & - & 6,3 & 5,1 & - & - & 4,4 & 3,5 & 3,0 & 5,12 & 2,9 \\
\hline Uréia $\quad(\mathrm{mg} / \%)$ & 8 & 一 & - & 一 & - & 23 & 一 & $3 \hat{i}$ & 30 & 22 & 15 \\
\hline Colesterol (mg/\%) & 195 & - & - & - & - & - & - & 125 & 180 & - & 140 \\
\hline Triglicérides $(\mathrm{mg} / \%)$ & $68 \hat{\jmath}$ & - & - & - & - & 一 & - & 450 & - & - & 70 \\
\hline Bilirrubina direta $(\mathrm{mg} / \%)$ & 3,2 & - & - & 0,50 & - & 0,65 & 0,14 & 0,20 & 0,12 & 0,70 & 0,14 \\
\hline Bilirrubina indireta $(\mathrm{mg} / \%)$ & 0,77 & - & 一 & 0,82 & - & 0,10 & 0,30 & 0,40 & 0,64 & 0,20 & 0,86 \\
\hline T.G.O. $(\mathrm{U} / \mathrm{ml})$ & 71 & - & - & 20 & - & 24 & 16 & 34 & 26 & 40 & 20 \\
\hline T.G.P. $\quad(\mathrm{U} / \mathrm{ml})$ & 180 & - & - & 18 & - & 4 & 12 & 20 & 10 & 20 & 18 \\
\hline Sódio (mEq/1) & 142 & - & 一 & 136 & 141 & 138 & 140 & 132 & 132 & 142 & 144 \\
\hline Potássio $(\mathrm{mEq} / 1)$ & 3,5 & - & - & 2,5 & 4,1 & 2,8 & 3,5 & 5,2 & 4,1 & 3,4 & 5,1 \\
\hline $\begin{array}{l}26 / 06 \\
30 / 07\end{array}$ & $\begin{array}{l}\text { Eletrofor } \\
\text { Eletrofor } \\
\qquad \begin{array}{l}I^{*} \\
I^{*}\end{array}\end{array}$ & $\begin{array}{l}\text { ese de } \\
\text { ese de } \\
=\text { Inici } \\
=\text { Susp }\end{array}$ & $\begin{array}{l}\text { proteina } \\
\text { proteina } \\
\text { to da n } \\
\text { ensão }\end{array}$ & $\begin{array}{l}\text { s: } \quad \alpha_{1}= \\
\text { s: } \quad \alpha_{1}= \\
\text { utriçāo p } \\
\text { a nutriç }\end{array}$ & $\begin{array}{l}0,39 \\
0,32 \\
\text { arentera } \\
\text { to pare }\end{array}$ & $\begin{array}{l}x_{2}=0,70 \\
x_{2}=0,67 \\
: \text { dia } 11 \\
\text { teral: di }\end{array}$ & $\begin{array}{c}\beta=0 \\
\beta=0 \\
06 / 82 \\
13 / 07 / 8\end{array}$ & $\begin{array}{l}\gamma= \\
\gamma=\end{array}$ & $\begin{array}{l}3,43 \\
3,38\end{array}$ & & \\
\hline
\end{tabular}

O joelho direito foi submetido à punção e a exame radiológico e, pela análise dos resultados, foi feito o diagnóstico de sinovite reacional.

No dia 19 de abril de 1982, foi iniciada a terapêutica com anfotericina $\mathrm{B}$, conforme esquema preconizado por MARCONDES \& col. ${ }^{7}$. No dia $1 .^{\circ}$ de maio de 1982, após aproximadamente 15 dias de tratamento, o doente apresentou quadro de abdome agudo obstrutivo, com presença de ascite. Este involuiu espontaneamente alguns dias depois, repetindo se uma semana mais tarde. No dia 12 de maio de 1982, o doente ainda estava em mau estado geral, ta. quicárdico, dispnêico, apresentanđo temperatura elevada de $39,5^{\circ} \mathrm{C}$ e dor intensa no hemi-tó- rax direito. As semiologias clínica e radiológica revelaram presença de sindrome de condensação de base direita e de massa tumoral, de aproximadamente $5 \mathrm{~cm}$ de diâmetro, de contor no intra-torácico bem definido, localizada na parede posterior do terço médio do tórax do lado esquerdo, tendo reflexão pleural, sugerindo lesão extra-pleural (Figs. 1A e 1B). O leucogra. ma apresentava leucocitose intensa, com desvio à esquerda escalonado. Foi iniciada então, terapêutica com penicilina cristalina e oxacilina Três dias mais tarde, o doente melhorou dos quadroş abdominal e torácico, havendo discre ta melhora do estado geral, voltando a se alimentar normalmente. No dia 23 de maio de 1982, foi puncionada a massa tumoral da regiäo 
PEREIRA, P. C. M.; BARRAVIERA, B.; MARCONDES, J; LETTE, C. V. S.; MEIRA, D. A.; INOUE, T. \& MORCELI. J. - Paracoccidioidomicose subaguda progressiva. Tratamento de um doente com anfotericina $B$ e nutriçāo parenteral. Riv. Inst, Med. trop. Sšo Panto 27:268-273, 1985.
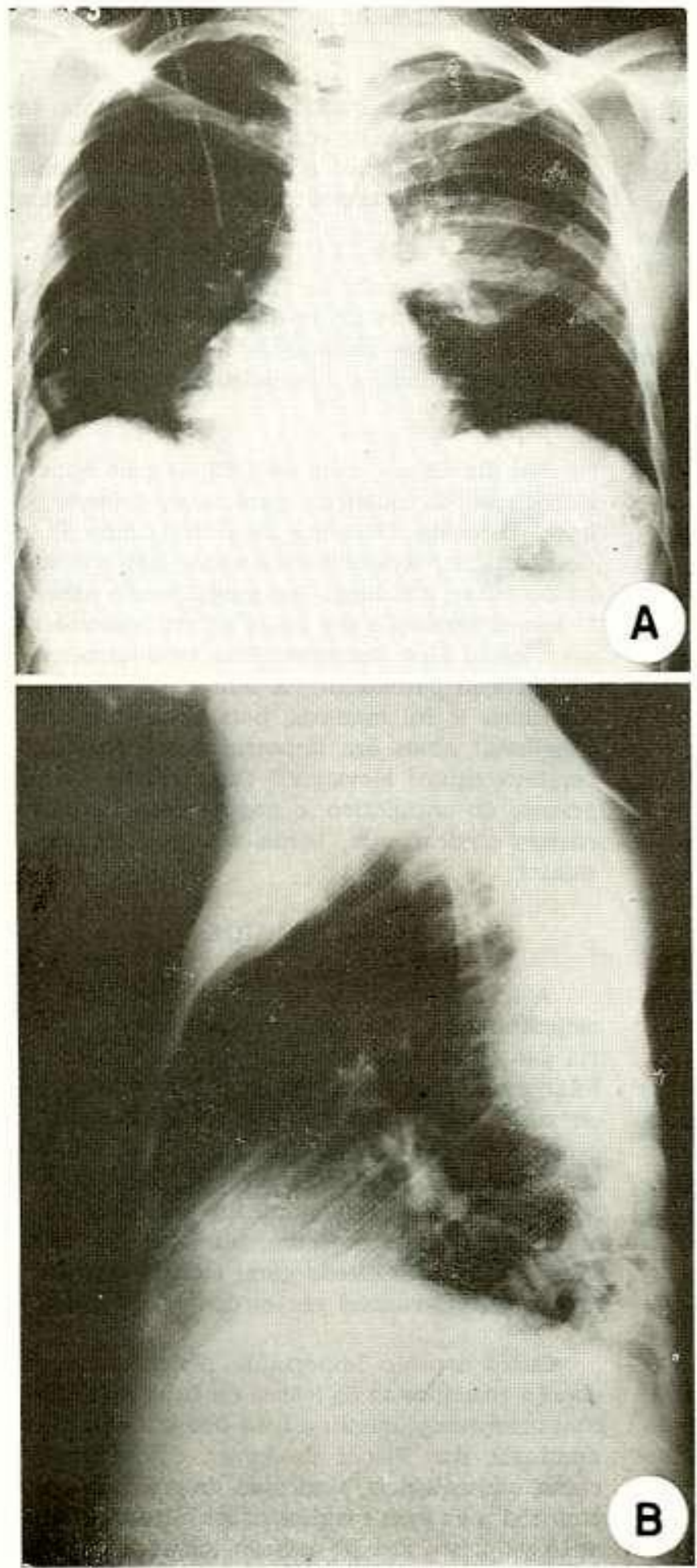

Fig. 1 - A) Radiografia do tórax (AP). Opacidade projetada na regiâo hilur e para-hilar esquerda. Obliteraçáo do selo costo frénico direito por derrame pleural. Muitiplas lesdes liticas nos areos costais. B) Radiografta do tórax (perfil). Opacidade homogênea de contorno intratoricico bem definido localizada $\mathrm{na}$ parde posterior do terço médio do tórax, com reflexûc pleural. 
PEREIRA, P. C. M.; BARRAVIERA, B.; MARCONDES, J.; LEITE, C. V. S.; MEIRA, D. A.; INOUE, T. \& MORCELI, J. - Paracoccidioidomicose subaguda progressiva. Tratamento de um doente com anfotericina $B$ e nutrição parenteral. Rev. Inst. Med. trop. Sāo Paulo 27:268-273, 1985.

inter-escapular esquerda, obtendo-se $70 \mathrm{ml}$ de material purulento que, ao exame micológico direto, mostrou Paracoccidioides brasiliensis. Em 1. de junho de 1982, o doente apresentava-se em anasarca e ascite importante, dificultando a respiração. À drenagem obtiveram se $1.300 \mathrm{ml}$ de líquido amarelo citrino compatí. vel com exsudato após exame laboratorial. Nesta ocasião, o doente recebeu albumina. Dois dias depois, apresentou novamente quadro clínico compatível com abdome agudo obstrutivo. A cirurgia foi contra-indicada devido ao mau estado geral do doente. Nessa ocasião, a dose total de anfotericina $B$ já administrada era de $1.055 \mathrm{mg}$.

Na tentativa de melhorar o estado geral do doente, optou-se pela realização de nutrição parenteral, a qual foi iniciada em 11 de junho de 1982.

Desse modo, através de cateter central, o doente passou a receber, nas 24 horas, solução assim composta:

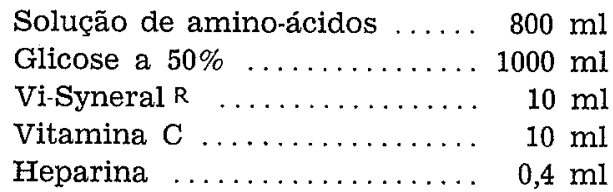

Cloreto de potássio, Sulfato de Magnésio, Gluconato de cálcio = de acordo com os exames laboratoriais subsidiários realizados diariamente.

Além disso, por veia periférica, o doente continuou a receber anfotericina $B, 400 \mathrm{ml}$ de emulsão de lípides três vezes por semana. Uma vez por semana, recebia $500 \mathrm{ml}$ de plasma fresco por via intra-venosa, assim como Vitamina $K$, Vitamina $B_{12}$ e ferro injetável, este último, por via intra-muscular profunda.

Em 16 de junho de 1982, cinco dias após o início da terapêutica parenteral, o doente apresentou sensivel melhora clínica, desaparecimento do quadro de abdome agudo e reinício da alimentação por via oral, complementando a nutrição parenteral. Neste mesmo dia apresentou quadro de cansaço, dispnéia, febre de $38,5^{\circ} \mathrm{C}$, dor na base do hemitórax esquerdo que piorava à inspiração profunda. Ao exame físico do tórax, apresentava síndrome de condensa- ção de base esquerda, confirmada pelo exame radiológico. Iniciou se, então, terapia com cefalotina.

No dia 20 de junho de 1982 , o doente encontrava-se animado, com melhora dos quadros abdominal e torácico e regressão dos volumes de gânglios e da massa tumoral da região dorsal.

Em 25 de junho de 1982, não apresentava mais febre, tendo ainda dores abdominais discretas e funções fisiológicas normais. A ascite estava regredindo e o estado geral do doente era bom.

No dia 13 de junho de 1982, 31 dias após a introdução da nutrição parenteral, quando já havia recebido $1.805 \mathrm{mg}$ de anfotericina $\mathrm{B}$, o doente alimentava-se normalmente, não apresentando ascite, a maioria dos gânglios encontravase em cicatrização e a febre estava ausente há mais de 20 dias. Optou-se então pela suspensão da nutrição parenteral. A terapêutica com anfotericina $B$ foi mantida, pois o enfartamento ganglionar ainda era importante e a sorologia revelava títulos elevados. Com a dose de 4,0 gramas do antibiótico, o doente apresentava-se curado clinicamente, tendo recebido alta hospitalar.

\section{COMENTÁRIOS}

A forma subaguda progressiva da paracoccidioidomicose, com comprometimento da maioria das cadeias ganglionares, ossos e tecido celular subcutâneo, tem em geral mau prognóstico com letalidade elevada ${ }^{2}$. Nestes casos a evolução final quase sempre é acompanhada de síndrome septicêmica, tumor abdominal e abdome agudo ${ }^{1}$. O emagrecimento acentuado evoluindo para caquexia, febre, adinamia e o comprometimento do estado geral contribuem para evolução desfavorável nestes doentes.

Outro aspecto importante nesta forma de doença relaciona-se às lesões do tubo digestivo, com comprometimento difuso dos linfáticos ab dominais, das Placas de Peyer, determinando como consequiência sindrome de má absorção com todas as suas manifestações ${ }^{5}$. No caso des crito as crises de sub-oclusão intestinal prova velmente foram devidas à compressão extrínse. ca do tumor intra abdominal. 
PEREIRA, P. C. M.; BARRAVIERA, B.; MARCONDES, J.; LEITE, C. V. S.; MEIRA, D. A.; INOUE, T. \& MORCELI, J. - Paracoccidioidomicose subaguda progressiva. Tratamento de um doente com anfotericina B e nutrição paren teral. Rev. Inst. Med. trop. São Paulo 27:268-273, 1985.

Tendo em vista os resultados obtidos no presente caso, em que a melhora clínica e la. boratorial provavelmente foi devida à alimentação parenteral, pois, o doente não se beneficiara com o tratamento antifúngico especifico, os Autores propõem o uso dessa medida auxiliar em casos semelhantes.

\section{SUMMARY}

Subacute progressive paracoccidioidomycosis. Treatment of a patient with amphotericin B and parenteral feeding

The Authors describe a case subacute progressive paracoccidioidomycosis with a clinical picture suggesting a malabsorption syndrome whereby the patients did not benefit from conventional antifungal treatment. Clear improvement shown by clinical signs and laboratory tests occurred when parenteral feeding was introduced as a supporting measure. Thus, the Authors propose the use of parenteral feeding in association with conventional treatment for the treatment of patients with this clinical form of paracoccidioidomycosis.

\section{REFERENGIAS BIBLIOGRAFICAS}

1. BARBOSA, W.; DAHER, R. \& OLIVEIRA, R. A. - For ma linfático abdominal da Blastomicose Sul Americana. Rev. Inst. Med. trop. São Paulo 10: 16-27, 1968.
2. CASTRO, R. M. \& DEL NEGRO, G. - Particularidades clínicas da paracoccidioidomiccse na criança. Rev. Hosp. Clin. Fac. Med. São Paulo 31: 194-198, 1976.

3. DUDRICK, S. J. \& RUBERG, R. L. - Principles and pratice of parenteral nutrition. Gastroenterology 61: 901, 1971.

4. FAINTUCH, J. J. - Aspectos imunológicos do desnutrido. In: Alimentaçāo Parenteral Prolongada. Editado por Joel Faintuch. 1.a ed. São Paulo, Editora Manoel, Cap. 26,1980 , p. $245-249$

5. FIORILLO, M. A.; MARTINEZ, R. \& MORAES, C. R. - Lesões do aparelho digestivo. In: Paracoccidioidomicose (Blastomicose Sul Americana). Editado por Gildo Del Negro, Carlos da Silva Lacaz e Adhemar Mário Fiorillo. São Paulo, Sarvier, Edusp, Cap. 18, 1982, p. 179-193.

6. GIRALDO, R. \& col. - Pathogenesis of paracoccidioidomycosis: a model based on the study of 4 , patients. Mycopatologia (Den Haag) 58: 63-70, 1976.

7. MARCONDES, J.; BARRAVIERA, B.; MEIRA, D. A. \& MENDES, R. P. - Emprego da Anfotericina B corrigida pelo clearence da creatinina em doentes com Paracoccidioidomicose. Anais do XVIII Congresso da Sociedade Brasileira de Medicina Tropical. Comunicaçä- F-19, Ribeirão Preto, 1982.

8. MISHLIS, S. P.; SKYRING, A. P. \& STEPHEN, D. D - Intestinal lymphangiectasia: mechanism of enteric loss of plasma protein and fat. Lancet 1: 77, 1965.

9. STROBER, W.; WOCHNER, R. D.; CARbONE, P: P. \& WALDMANN, T. A. - Intestinal lymphangiectasia: a protein-losing enteropathy with hypogammaglobuline. mia, lymphocytopenia and impaired homograft rejec tion. J. Clin. Invest. 46: 1643, 1967.

Recebido para publicação em 31/8/1984. 